\title{
REFORMULAR, RELANZAR, REORGANIZAR O, ¿TRANSFORMAR HONDURAS?
}

José Luís Martínez ${ }^{1}$

En el diario vivir de los hondureños es muy común identificar a las personas a partir de sus posicionamientos en derredor de aspectos que tienen que ver con los problemas que atañen al país y no como quieren algunos hacernos creer que en nuestro país la identidad de los ciudadanos gravita alrededor de su militancia en los partidos tradicionales. Esa pretendida identificación además de ser una falsa premisa, constituye más bien un propósito diversionista que no busca otra cosa que no sea la distracción de los grandes objetivos hacia los que debe orientarse la nación. Los recientes acontecimientos políticos que sacudieron la conciencia nacional han servido para que la demarcación no deje lugar a dudas, puesto que en definición del golpe de estado que depuso a las autoridades legítimas del país, ha estado implícito el tránsito de cualquier eufemismo teórico a una práctica o realidad que no se puede ocultar y del lado del golpe se han alineado hasta los más acérrimos enemigos de las mas tibias reformas, además de aquellos tradicionales conservadores, que en concordancia con sus intereses, se aferran a un status que se desmorona en pedazos, como resultado de su agotamiento histórico.

Sin embargo, del lado de quienes han visualizado que la realidad nacional ya no es más aquel juego insulso en donde los políticos criollos hacían y deshacían a su antojo, a partir del golpe de estado de junio 2009, puesto que el país se ha enrumbado por la senda de la transformación, subsisten gradualidades en cuanto a la percepción y profundidad de dicha transformación. Otros tantos creemos que en el proceso de transformación y en la misma medida en que ese proceso reditúe beneficios tangibles

\footnotetext{
${ }^{1}$ Profesor del Posgrado Centroamericano de Economía (POSCAE-UNAH).
} 
en materia de participación política, económica, de decisiones, de ejercicio del poder y de oportunidades para todos los ciudadanos y de una lucha frontal contra la corrupción, el frente de lucha por la transformación de nuestro país se verá fortalecido, de tal manera que será materialmente imposible frenarlo e históricamente irreversible. Naturalmente que para alcanzar ese nivel se deben operar transformaciones materiales que no pueden esperar una rápida evolución de la conciencia nacional, porque la vida nacional necesita ser oxigenada por esas transformaciones, de lo contrario perecerá y el final llegará para todos, incluidos los mismos conservadores.

Desde el propio momento en que las estructuras sociales y económicas que tipificaban a la sociedad de quienes poblaban lo que hoy llamamos Honduras, se vieron truncadas, abolida y exterminada su cultura, como resultado de la colonización y de la adulteración bio psico social de la población, se ha incubado una tendencia reformista, en la cual siempre ha estado presente la nostalgia conservadurista y el desprecio por la transformación.

La historia contemporánea de Honduras registra que la forma o las vías por las cuales se han distribuido los recursos, ha respondido, no a la dinámica y desarrollo natural que exhibía y caracterizaba a la sociedad precolombina, sino a la superposición de un sistema que se construyó sobre la base de unas relaciones de producción que estaban encaminadas a apuntalar el fortalecimiento del desarrollo del mercantilismo de la corona de España. Este proceso reporto implicaciones tanto en lo económico como en el ámbito social. Mientras en lo social, el régimen impuesto condicionaba una estructura social donde dos estratos: los colonizadores y los indígenas configuran una unidad que está en constante lucha, en el aspecto económico implicó el avasallamiento de la sociedad y las relaciones de producción precedentes de los indígenas fueron sustituidas por una especie de esclavismo colonizador, 
probablemente retrotrayendo la sociedad precolombina, a estadios en su devenir histórico ya transitados y superados.

Esta situación determinó, que por una parte la economía sufriera una metamorfosis que como resultado de tal imposición, padece una dualidad estructural que se manifiesta en el hecho de que las relaciones de producción que imponen los colonizadores, si bien no son típicamente esclavistas, la forma de propiedad sobre el recurso tierra se ejerce de forma concentrada, puesto que se despojó a los indígenas y a las comunidades de sus tierras y éstas pasaron a ser "propiedad" de los colonizadores, es decir, aquí la expropiación y en consecuencia la apropiación, sirvieron de mecanismo que abrió la brecha a la forma de propiedad privada sobre los medios de producción, de manera que el advenimiento de una formación socioeconómica nueva, no ha sido el resultado de procesos normales en la dinámica social, de acumulación y de ruptura de ese equilibrio a medida en que las relaciones de producción imperantes y el desarrollo observado por las fuerzas productivas ya no guardan armonía y el nivel de esa contradicción ya no se puede resolver si no es en el marco de un nuevo modo de producción. Por otra parte, en la base económica sobrepuesta persisten rasgos de la economía precolombina, en donde aún se conservan las evidencias de una sociedad de mayor equidad.

Una estrategia político-ideológica-epistémica condiciona el pensamiento dominante en América Latina desde 1492, según José de Souza Silva ${ }^{2}$, veamos en qué consiste tal estrategia. El autor parte de una premisa fundamental acerca de la idea de desarrollo contenida en dicho paradigma. Las premisas sobre las cuales se construye esta categoría de desarrollo dice son falsas y por tanto, las promesas hechas en torno a la

\footnotetext{
${ }^{2}$ La investigación científica para el desarrollo y el desarrollo de la investigación científica. Geopolítica del conocimiento y los aportes de la ciencia a la gestión del desarrollo en América Latina. José de Souza Silva. Red Nuevo Paradigma para la innovación institucional en América Latina.
} 
temática son también falsas, como inadecuadas resultan siendo las soluciones propuestas alrededor de esta temática.

En consistencia con lo anterior, "un esfuerzo de etnografía institucional y de descolonización epistémica desentraña la trama de relaciones, significados y prácticas de la geopolítica del conocimiento que nos presiona a pensar como ELLOS para ser como ELLOS. Desde 1492 el poder está con los que generan y usan su propio conocimiento científico (Bell 1995). El Banco Mundial, uno de los constructores del orden institucional corporativo, representa al vencedor de la II Guerra Mundial y sus aliados, los desarrollados, que ayudan a los subdesarrollados a ser como ellos".

"Según Goonatilake (1984), si a un mapa de desigualdad fuera sobre puesto un mapa de la generación y uso de conocimiento propio, ambos coincidirían. El más fuerte usa su poder político, económico, militar y científico para la institucionalización internacional de la desigualdad que permite al dominador acceder de forma inescrupulosa a los mercados cautivos, materia prima abundante, mano de obra barata, mentes dóciles y cuerpos disciplinados de los dominados, violando lo humano, lo social, lo cultural, lo ecológico y lo ético. Un ejemplo de eso es ofrecido por el Banco Mundial. En su Informe de Desarrollo Mundial-Conocimiento para el Desarrollo, el Banco propone la continuidad de este orden "natural" de las cosas, a partir de falsas premisas:

"Los países pobres difieren de los países ricos...porque tienen menos conocimiento. La generación de conocimiento es muy cara, y este es el porqué la mayor parte del conocimiento es generado en los países industriales. El Informe del Desarrollo Mundial propone que miremos los problemas del desarrollo desde la perspectiva del conocimiento. Los países en desarrollo no $\underline{\text { necesitan reinventar la rueda. En vez de recrear el conocimiento ya existente, }}$ 
los países más pobres tienen la opción de adquirir y adaptar...conocimiento ya disponible en los países más ricos. Adquirir conocimiento implica acceder y adaptar conocimiento disponible...a través de un régimen abierto para el comercio, inversión extranjera y (licensing agreements)...asegurando que el pobre tenga acceso. La distribución desigual de la información no puede jamás ser eliminada, pero puede ser mejorada" (Worid Bank 1994:1-14; el subrayado es del autor (Souza Silva).

"El Banco Mundial promueve la dicotomía superior-inferior (desarrolladosubdesarrollado, a partir de falsas premisas: (i) conocimiento es sinónimo de información; (ii) el conocimiento científico es universal y neutral; (iii) el conocimiento científico generado desde los países inferiores es idéntico al generado desde los países superiores, razón por la cual estarían necesariamente reinventando la rueda; (iv) existen países superiores, que generan conocimiento válido para todas las realidades y países inferiores, que son receptores de lo generado por los primeros; (v) la causa de todos los problemas complejos de los países inferiores es la falta de conocimiento científico; (vi) el conocimiento que necesitan los países inferiores pobres- para ser como los países superiores -ricos- ha sido generado y está disponible en los países "desarrollados"; (vii) la forma práctica de los países inferiores de acceder al conocimiento que necesitan es comprándolo a los países superiores; (viii) la distribución desigual de la información - conocimiento - no puede ser eliminada, apenas mejorada (como si fuera un fenómeno "natural"). En síntesis, bajo la ideología del mercado, los ricos ya no ayudan a los pobres, como recomendó la Rerum Novarum en 1891. Siguiendo la geopolítica del conocimiento, la lógica de la mercancía ha profanado el santuario intangible del pensamiento. Todo se compra todo se vende, hasta el saber (del rico). Para que la pobreza sea transformada en fuente de 
riqueza, el rico ha definido que para ser como ELLOS, el pobre debe ahora pagar para imitarlos".

El proceso de sometimiento de la estructura social y económica con que se encontraron los colonizadores a su llegada al nuevo mundo por la vía de la esclavización, no solo implicó que la explotación de la fuerza de trabajo indígena sirviera para crear un excedente que se sustrajo del medio colonizado, lo que conllevó un acrecentamiento de la pobreza de los indígenas hasta llegar a su exterminio, además del execrable robo de los recursos minerales del país, que sirvieron para el afianzamiento de un sistema basado en la expansión y el avasallamiento por la vía del colonialismo. La dualidad y deformación estructural que se produce y se hereda desde la colonización no solo tiene repercusiones en el ámbito de la economía y la sociedad, también se genera una cultura híbrida que pendula entre los dos estratos, pero que, en tanto que parte de la infraestructura, esa influencia cultural no busca otra cosa que proporcionarle la legitimidad que requiere el orden impuesto por los colonizadores. En la base primaria de la sociedad hondureña se opera un corte, que más allá de las implicaciones económicas y sociales que esto conlleva, frena y desvía el curso natural de la dinámica socioeconómica de la sociedad precolombina autóctona.

De la misma forma en que la base económica termina influenciando en forma determinante a la superestructura, las manifestaciones de las diversas formas de la conciencia social también ejercen una influencia desde ese nivel hacia la base y tal influencia se evidencia en dos direcciones, una orientada a buscar cimentar y garantizar la reproducción y sostenibilidad del sistema en su conjunto, lo cual se da por la vía de las leyes, la educación, la moral, la política, religión, la ideología, etc., pero, dado que todo sistema socioeconómico es la unidad contradictoria de elementos y clases sociales con intereses encontrados, en esas distintas formas que reviste la conciencia social, también se incuba una ideología, una moral y una política que 
responde a los intereses de la o las clases sometidas o que no detentan el poder, por lo que la influencia que se ejerce desde esta perspectiva sobre la estructura social y económica, es en sentido de propiciar una sucesión de esta formación social por otra mucho más avanzada.

No obstante, no significa que en este proceso de lucha por el afianzamiento y conservación del sistema y/o por su transformación o sustitución por otro sistema que garantice o se estructure sobre una mayor participación, oportunidades y bienestar para todos los ciudadanos, también se incuben y adquieran presencia, posiciones intermedias que oscilan entre ambos postulados. En este tramo intermedio se explica el aparecimiento de una especie de cultura, que es la expresión en este ámbito, de la simbiosis entre los colonizadores y los colonizados.

Bajo este panorama, la visión que se plantea en derredor del problema nacional, tiene tres perfiles claramente determinados: i) por un lado se muestra una corriente conservadora ligada y a partir de su identificación con el status quo, puesto que es quien le garantiza usufructuar el poder mediante la estructura formal del estado en beneficio de su propios intereses, que no puede estar interesada si no es precisamente en la conservación del sistema; ii) frente a la primera aparece otro posicionamiento que se origina en la visión del mundo que poseen las clases dominadas y que dado que el sistema les excluye de la distribución de los recursos o cuando menos, no es suficientemente equitativo en cuanto a la creación de oportunidades, son partidarias y les conviene la supresión del sistema y el advenimiento de otro más participativo y equitativo; entre ambas posturas aparece iii) una posición intermedia que vacila entre los extremos, esa es precisamente la tendencia que considera que los cambios superficiales manteniendo inalterada la base que condiciona la explotación y la exclusión social, limpian la cara del sistema y lo 
hacen aparecer más humano, están mucho más cerca del conservadurismo que de la transformación, es más, son esencialmente opositores a la transformación.

Las reformas per sé no es que sean malas o resulten intrascendentes, de hecho en circunstancias especiales, las reformas revisten una importancia capital para las sociedades y se convierten en logros inapreciables para las sociedades en su conjunto, pero no hay que perder de vista, que tienen un contenido histórico muy concreto, de manera que cuando las condiciones que determinan la aplicación de cualquier reforma, siendo que no pueden permanecer invariables e inmutables en el tiempo, cambian, ya se vuelven superfluas puesto que se agotan. De ahí que pensemos, que como todo en la vida, las reformas tienen su oportunidad, y una vez que dicho tiempo ha transcurrido, dejan de ser aplicables y ya no son más que patrañas con las que se pretende detener la dinámica de la sociedad y de la propia naturaleza.

De aquí podemos sacar algunas conclusiones respecto de los planteamientos de los partidos políticos en el país en lo cual se puede observar que la carencia de un norte conductor que guie las acciones, no del gobierno, sino del Estado, es el fiel resultado y la evidencia de que se actúa en función de intereses sectarios y con una gran dosis de demagogia política en la gestión pública. Todas las acciones y políticas que se adopten en el plano nacional no deben tener ni la impronta ni menos el estigma de un gobierno o de un partido en particular, el Estado no es un reducto ni siquiera de los grupos de poder que lo usufructúan, de ahí que las políticas deben adoptarse y llevarse a la práctica como políticas de estado y por lo tanto deberían devenir obligatorias para los gobiernos sucesivos.

Esta situación antes señalada la podemos observar claramente en las políticas sectoriales que se llevan a cabo en el país aun en aquellos gobiernos que han sido 
ejercidos por un mismo partido político en forma sucesiva, tal como ha sucedido con el planteamiento sobre la educación de nuestro país, con lo que no solo se muestra una falta de coherencia entre las propuestas y su desconexión con objetivos nacionales, sino también un despilfarro de recursos y un desprecio por sus antecesores; por ejemplo, el gobierno liberal de Don Carlos Roberto Reina tenía una plataforma educativa que le denominó la "Escuela Morázánica", mientras que el de Don Carlos Roberto Flores Facusse asumió sus funciones con la llamada "Nueva Agenda", haciendo borrón y cuenta nueva en esta materia.

Adicionalmente, si tenemos la dicha que los partidos políticos que participan en las elecciones "democráticas" que se operan en el país cada cuatro años, estructuren y conformen un programa de gobierno con el que deberían presentarse ante la sociedad para ganar su apoyo, fácilmente se puede observar que cada uno se "prepara" con grandes disparates y pareciera que la competencia se plantea en función de quién de ellos resulta más demagógico.

Recientemente en un evento académico realizado en la UNAH, un prominente abogado afirmaba que las reformas en Honduras, refiriéndose al sistema político, han agotado sus posibilidades y que el tiempo de las reformas debe dar paso al tiempo de las transformaciones. Esto parece tener mucha lógica y consistencia. La existencia de tantas leyes en el país, aunado a la forma tan sui gèneris que reviste la aplicación de la justicia, el manoseo y la manipulación política de los poderes públicos, el sometimiento de la administración pública a intereses bastardos, además de la corrupción, que se ha convertido en un mal que es inseparable de la gestión política (vernácula) y pública en las condiciones actuales, se han convertido en un impedimento colosal que pulveriza cualquier intento de reformar procesos, procedimientos en la gestión pública, reformar leyes, etc. Frente a este estado de cosas ya no queda otra que no sea la reformulación o transformación del sistema 
político actual que impera en Honduras, esto es lo que se puede concluir con lo expuesto por ese connotado jurista.

El tiempo de la transformación, más que una demanda es una necesidad para el país, no puede sobrevivir poco menos de la mitad de los hondureños con menos de un dólar por día, es insostenible y desde el punto de vista humano inadmisible que de cada 1000 niños nacidos vivos mueran 25 antes de cumplir cinco años, que mientras unas 300 mil familias campesinas no tienen tierra para producir y que subsistan miserablemente con lo que producen para su sostenimiento parcial y que adicionalmente, dada esa limitación e incapacidad del sistema económico de generar ingresos para que estas familias participen en la circulación mercantil, las mejores tierras con techos de propiedad que revelan el alto grado de concentración están en poder de un grupo de terratenientes y ganaderos que no le dan su función social; que la justicia se ensañe contra un simple ladrón que ha sido empujado a delinquir por las propias condiciones imperantes, mientras los ladrones del erario público son condecorados y hasta se les ha querido erigir estatuas y elevarlos a la categoría de "héroes nacionales", "hombres y empresarios del año" y otra serie de atrocidades. Una economía que como la nuestra con una estructura deformada y atrasada, condiciona que un poco más de $20 \%$ de la población, se quede con poco menos de $80 \%$ del ingreso nacional; en el otro plano destaca que casi el $80 \%$ de la población más empobrecida apenas percibe casi un $20 \%$ de la renta nacional. Esto no puede ser considerado como una visión moralista de la economía, es de suyo una visión amoral determinada por la economía del tener que se impone por sobre la economía para el ser. Por éstas, entre otras razones, la situación ya no es sostenible en las condiciones que imperan actualmente, de ahí que la transformación debe terminar imponiéndose, no como slogan, ni como demanda panfletaria demagógica, sino como una etapa del desarrollo que es inherente a la sociedad y a la propia naturaleza. 


\section{LA GLOBALIZACION, LA “DESIDEOLOGIZACION” Y LA EXPANSIÓN DEL CAPITAL EN UN MUNDO UNIPOLAR}

Toda esta situación que exhibe la economía y la sociedad hondureñas tiene un vínculo directo con lo que acontece y se ha suscitado en el mundo contemporáneo en años recientes; en el ámbito de las relaciones internacionales y asociado al desarrollo del comercio y de las propias relaciones de poder en el mundo actual unipolar, debemos establecer que el produccionismo capitalista tiene su origen en la recurrencia de las crisis de superproducción, mientras que el consumismo ha sido la válvula de escape que ha permitido permeabilizar a la población, para elevar el mercado a nivel de una categoría suprema, lo que ha implicado la "imposición" de una especie de cultura hedonista de privilegiar el placer el desenfreno y todo tipo de excesos a nivel individual, que ha venido a sustituir cualquier búsqueda de beneficio para cualquier tipo de colectividad. Tales excesos tienen un amplio espectro y hasta las propias relaciones sociales han sido trastocadas en aras de la expansión del capital, que al final de cuentas es lo que cuenta como objetivo fundamental, la obtención de esa ganancia extraordinaria capitalista.

Precisamente sólo en esa perspectiva de análisis se puede justificar que se destinen grandes cantidades de tierra en el mundo actual para la producción de alimentos, precisamente en momentos en que la cantidad de hambrientos en el mundo se ha incrementado sustancialmente, con el fin de producir bioenergéticos para satisfacer la demanda de automóviles producidos en el primer mundo. Mientras el modelo de libre mercado ha propalado a los cuatro costados que el mercado es la panacea de todos los problemas del mundo actual, casi la mitad de la población de los países del tercer mundo no participa de las relaciones mercantiles dado que no tienen ingreso alguno que les confiera la "libertad" que les corresponde como agentes libres en tal tipo de mercado. 
En épocas recientes este tipo de discernimiento era catalogado con el membrete de subversivo y en las agendas de los organismos internacionales parecían no tener cabida conceptos como la distribución del ingreso, equidad, participación, sin mencionar lo relacionado con los cambios estructurales. Dada la dinámica de la expansión del capital y la transnacionalización de la economía, la obtención de la cuota de ganancia obliga a adoptar y adaptar modelos a dicho objetivo y los críticos "convencidos" de cualquier reforma estructural ahora resultan siendo promotores de reformas y ajustes ESTRUCTURALES, ahora son los apóstatas guardianes de su majestad el capital. Esas reformas, siempre que se realicen en beneficio del capital y sin importar el sacrificio de vidas humanas, ahora se promueven desde las esferas de los organismos internacionales de crédito. Después de unas tres o cuatro décadas de "reformas estructurales" que no han podido hacer evidente aun el "rostro humano" del desarrollo capitalista, sobre todo en los países de mayor atraso, como Honduras, en el mundo actual se ha abierto camino una conciencia crítica que comienza a demandar una sociedad de mayor equidad y justicia. La desideologización en el mundo contemporáneo no debemos entenderla como la superposición de la ideología o apología del capitalismo sobre la ideología de la transformación del entorno socioeconómico de los hombres, sino como la variación en el enfoque respecto de hacia dónde hacer énfasis en lo que debemos transformar; eso le da sustento al tratamiento del Papa Juan Pablo II relacionado con el capitalismo contemporáneo, al que ha catalogado como "salvaje".

Con toda esta variación y el aparecimiento de corrientes esnobistas, que nos hablan de los modelos económicos como si se tratara de modas, frente a los daños que se han causado, tanto al entorno natural que nos rodea, como en la calidad de vida que estamos heredando a las generaciones venideras, el mundo actual enfrenta una oleada esperanzadora, que nos permite soñar con un mundo mejor; ya se están 
planteando y aceptando en la etapa final de desarrollo del capitalismo, que la "propuesta" de desarrollo que nos ha venido del norte, etiquetado como ajuste estructural, neoliberalismo, etc, lejos de contribuir a mejorar, más que las condiciones de la economía, las condiciones de los seres humanos, más bien ha implicado un panorama económico social de mayor concentración y de predominio de la pobreza.

En esta perspectiva de análisis, parece ser que la oportunidad de las reformas ha cedido su paso a la necesidad de las transformaciones en el mundo actual; el tiempo de las reformas ya hace mucho que pasó; ya las reformas son insuficientes para salvar al sistema del colapso, por ello es que las transformaciones son la expresión de la necesidad histórica de avanzar en el desarrollo social hacia estadios de mayor nivel y que son consustanciales con el bienestar del género humano, de ahí que cualquier intento reformista no hace más que buscar eternizar el capitalismo y en eso radica su esencia conservadurista. Ahora bien, ¿en dónde radica la causa de este deceso del capitalismo?, el origen o causa de su muerte es lo que alguien alguna vez lo llamó la contradicción fundamental del capitalismo, la cual consiste en que la producción de bienes y servicios que la sociedad requiere para su sobrevivencia adquiere progresivamente un carácter cada vez más social, mientras la distribución del producto se opera de forma cada vez más concentrada.

Sobre la base de este razonamiento antes expuesto, fácilmente podemos determinar y comprender las razones que subyacen detrás de tantas "visiones" de país que nos encontramos en el quehacer diario de los hondureños, desde la plataforma pública, los gobiernos según su matiz político partidario y los intereses que representan, que basta decir son los mismos para todos los partidos políticos tradicionales, "construyen" su propia "visión", que no es más que el o los escenarios que necesita el capital para continuar en su senda de expansión y que le garantice la obtención de esa cuota de ganancia, que es el sentido y la racionalidad del modo de producción capitalista. En 
nuestros días, los nacionalistas encaramados en el poder como resultado de un proceso eleccionario desnaturalizado y deslegitimado por el silencio cómplice que mantuvo el partido nacional frente al golpe de estado urdido por las fuerzas retrógradas del país, vinculadas estas acciones a los planes y maniobras maquiavélicas de la embajada de los Estados Unidos, han lanzado a la palestra pública con bombos y platillos su así llamado Plan de Nación, que muy en el fondo es "su" versión y el escenario que requiere y demanda el capital en su proceso de expansión.

En años recientes el Foro Nacional de Convergencia FONAC ha trabajado intensamente en la formulación de una "visión de país" sobre la base de una metodología participativa e incluyente, que le había reportado muy buenos resultados en la formulación de una muy seria propuesta de transformación del sistema educativo nacional de Honduras, desafortunadamente y por esa mala costumbre de las autoridades hondureñas a cualquier nivel, que cuando se formulan propuestas serias sobre cualquier temática de interés nacional, no falta quienes se atraviesan en el camino y si sienten o visualizan que dicha propuesta puede afectar o reducir sus influencias o los beneficios que les reporta una situación contraria a tal propuesta, si no la pueden desechar de una sola vez, la dejan viviendo el sueño de los justos, traspapelada y condenada al olvido y la acción destructora de la polilla, o mejor dicho y en un lenguaje más oportuno y a tono con la época "moderna", los virus terminan con cualquier vestigio de "vida" en el espacio cibernético.

La visión de país que se ha proyectado desde la esfera pública, por ejemplo a través de la Estrategia de Reducción de la Pobreza ERP, es la de una Honduras, no sin pobres, sino con la "reserva" de pobreza que necesita el sistema y sin la cual no puede mantenerse en pie, de ahí que en esos "planes" y "estrategias" no se pueden definir metas de erradicación o supresión, pero sí de mitigación y/o reducción de la pobreza. 
Con ese asunto de la pobreza, tanto los gobiernos como los propios organismos internacionales, quienes son los verdaderos padres de esos planes reduccionistas de la pobreza, han hecho mucha demagogia y se han cometido las tropelías más grandes en nombre de un objetivo, que más que noble es de signo vital para la economía capitalista y más que eso, debe ser un compromiso nacional, puesto que la vida de los ciudadanos es determinante para la vida del país y los pobres de nuestro patio son también seres humanos e hijos de esta tierra llamada Honduras.

La llamada Iniciativa para los Países Altamente Endeudados (HIPC por sus siglas en inglés), se adopta por los países desarrollados y los organismos multilaterales en contubernio con la banca privada internacional a partir de una premisa que a todas luces parece ser falsa, la de que somos incapaces, desde el punto de vista de la cuantía de recursos necesarios para hacer efectivo el pago de la deuda, de cancelarla. Ante la imposibilidad de poder pagar tal deuda se la "condona", con la única condición de que tales recursos se apliquen en el país en la lucha contra la pobreza. Entonces, cabe la pregunta, ¿somos o no lo suficientemente capaces de cancelar la deuda?, se nos condona por carecer de esa capacidad de pago, pero sí se supone que tenemos la capacidad de generar los cinco mil y pico millones de dólares frescos para destinarlos a la reducción de la pobreza. Al sistema productivista y consumista del capitalismo no le interesa ni le conviene que las personas, en tanto que son consumidores, perezcan o mueran y resulta mejor invertir en recuperar la capacidad de pago y de consumo de los pobres de la tierra, para oxigenar el capitalismo y prolongar su vida en el tiempo y la obtención de la cuota de ganancia que le da sentido y constituye la esencia misma del sistema.

Es así que los pobres, no es que le interesen al sistema desde el punto de vista humano, solamente interesa potenciar a esas personas como consumidores y a la economía capitalista le conviene insertarlos en las actividades productivas, por ser 
precisamente una fuente generadora de valor de cambio. La sucesión y recurrencia de las crisis al interior del capitalismo y la agudización de su contradicción fundamental han conducido a una recomposición en el mundo entero en el cual la falacia que habían concebido los clásicos respecto del desarrollo social más allá del capitalismo se resquebrajó a principios del siglo pasado con el advenimiento de un nuevo modo de producción, que pulverizó el mito del capitalismo como el fin de la historia. El agotamiento del modelo de sustitución de importaciones en América Latina, el desarrollo desigual, aunado a la profunda crisis de desempleo e inflación que se desencadenó en los países desarrollados y la crisis de la deuda externa que explosionó en nuestros países, puso de relieve la actualidad y la importancia de las transformaciones y hasta sirvió para que se abriera de nuevo la oportunidad para las reformas, es precisamente en este contexto donde aparecen las así llamadas transformaciones estructurales que se contienen en los Programas de Ajuste Estructural que se comienzan a extender por América Latina en la penúltima década del siglo pasado.

Los mencionados programas de ajuste estructural una vez agotados, una vez que el nivel de inversiones realizadas no se corresponde con los niveles de avance, sobre todo en el ámbito social en donde las sociedades parecen haberse vuelto mucho más concentradas y donde a pesar de los cambios que se han operado a nivel institucional en toda América Latina, la recurrencia de los desajustes está intacta, es más, ahora contamos con un panorama mucho más complejo con la irrupción de la corrupción como un mal que no sólo afecta al sector público y se extiende por toda la sociedad, la discusión acerca de la oportunidad y aplicabilidad de las reformas en nuestro medio parece estar llegando a su límite, puesto que las condiciones que exhibe la crisis carcome los propios cimientos del sistema y la "capacidad" de maniobra de los grupos de poder de frenar los cambios mediante reformas retardantes, se ha visto muy 
reducida, a menos que se recurra al expediente del ejercicio de la fuerza y la violencia, como ocurrió en junio del 2009, cuando los grupos militaristas de los partidos tradicionales recurrieron a los trasnochados golpistas, para echar al traste un intento REFORMISTA del depuesto Presidente Manuel Zelaya.

En la misma medida en que la acumulación y expansión del capital ensancha las diferencias nacionales y entre los propios pueblos y países del globo terráqueo, la economía mundial se ve sometida a los designios del gran capital, las propias reformas de las que requiere el capital en ese proceso, ya trascienden las esferas nacionales y se imponen como una "necesidad" global y dichas reformas tienen un carácter supranacional y de nuevo la periferia queda sometida por el centro y ya nos abocamos a un proceso de sometimiento neocolonial, que solo va a ser cortado por movimientos de transformación que se tendrán que verificar en la mera estructura o base de nuestras sociedades y que deberá tener como finalidad la erradicación de la dependencia y la construcción de una senda de desarrollo nacional basado en nuestras propias potencialidades, gravitando en derredor de elementos identitarios, que nos permitan perfilar una imagen real de la Honduras que anhelan TODOS sus hijos.

Por todas estas razones, creemos que la época de las reformas ya ha caducado en nuestro país y ahora comienza a perfilarse en toda su magnitud la necesidad de operar transformaciones estructurales que tendrán que reportarle inevitablemente réditos a la nación; no se trata de ver con pesimismo y hasta con una visión apocalíptica acerca del futuro de nuestra patria, de lo que se trata más bien es de entender que las soluciones de nuestra problemática debemos construirlas a partir de nuestra propia realidad, sobre la base de un conocimiento exhaustivo de la realidad 
nuestra; sin embargo, escribe el doctor José de Souza Silva ${ }^{3}$ cualquier "análisis de la contribución de la investigación científica debe ser concebido a partir de la premisa de que la práctica científica no es democrática ni neutral, porque el orden institucional hegemónico no lo ha permitido. La democracia que el vencedor de la II guerra mundial y sus aliados promueven -o imponen- para nuestro "desarrollo" es practicada como

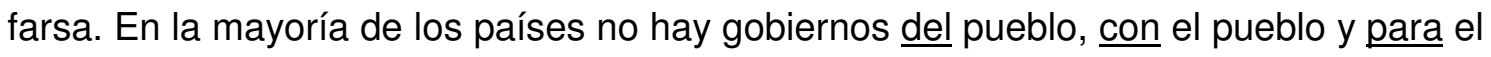
pueblo. Bajo la presión creciente del capitalismo global, hoy organizado bajo un orden institucional corporativo transnacional, lo que predomina es el gobierno de las corporaciones, con las corporaciones para las corporaciones (Barnet y Cavanagh 1995; Korten 1996; Sclair 2001; Bakan 2004). Pero la democracia liberal también está en crisis a lo largo y ancho del planeta, como parte del colapso de la civilización occidental, sus instituciones, conceptos, valores y modelos de desarrollo (Atalli et. al. 1980; Capra 1982; Filho et. al. 2003a, 2003b, 2003c; Dupas 2006). El siglo XX demostró que muchas de las premisas que sostienen la civilización occidental son falsas".

De manera que la idea de "desarrollo" que nos han exportado desde el viejo mundo "civilizado" no se ajusta a las condiciones que también se nos ha impuesto en nuestro continente, y la realidad en que nos desempeñamos los países tercermundistas no cuadra con la "realidad" definida por aquel paradigma. Esto es así, dado que "son falsas muchas de las premisas esenciales del marco de la civilización occidental para explicar la naturaleza y dinámica de la realidad, y para justificar y legitimar sus relaciones asimétricas de poder con otras civilizaciones y pueblos "no occidentales". El régimen de verdades de su proyecto moderno/colonial instituye la visión de mundo del colonizador (Blaut 1993; Mignolo 2000). Así, ya no es razonable continuar creyendo en sus promesas sin verificar la consistencia y relevancia de sus premisas". En

\footnotetext{
${ }^{3}$ Op. Sit.
} 
consistencia con todo esto, continúa el autor, "como ninguna promesa oficial hecha en nombre del "progreso" o del "desarrollo" ha sido cumplida (Danaher 1994; Caufield 1996), así como los Objetivos de Desarrollo del Milenio (ODMs) tampoco serán cumplidos, verifiquemos las premisas que sostienen sus promesas. Sin son falsas, las sospechas están confirmadas. Lo crítico es comprender que falsas premisas conllevan a falsas promesas y soluciones inadecuadas"4.

Para ir puntualizando algunas opciones o alternativas en materia de política económica que se deben adoptar en el país en la coyuntura actual, primero hemos de insistir en la necesidad de que se impulsen eventos, se creen espacios de diálogo, de concertación, pero sobretodo, de compromiso con el país, en los cuales se pueda abrir un debate franco y serio sobre la problemática nacional y que el Estado asuma una verdadera postura de compromiso de conducir los destinos de la nación por la senda de la responsabilidad, la transparencia y haciendo honor al compromiso de transformar el país, como condición indispensable para poder hacer realidad el escenario del logro del bienestar de TODOS los ciudadanos de Honduras. Por su parte, la ciudadanía, los hombres y mujeres de esta tierra debemos no solo movilizarse y organizarse para la concreción de tales objetivos de desarrollo nacional, adicionalmente debe convertirse ese movimiento social amplio en un garante viabilizador del proceso, que también deberá cumplir con el compromiso de velar por la transparencia, exigir la rendición de cuentas y, mediante una permanente auditoría social, incidir en el rumbo y en la toma de las decisiones correctivas y oportunas que correspondan, en el quehacer público. Finalmente, intentamos ensayar 0 delinear algunos puntos trascendentales 0 propuestas que en materia de transformación deben impostergablemente llevarse a cabo en nuestra patria:

\footnotetext{
${ }^{4}$ Op. Sit.
} 
1. Un proceso de redistribución eficiente del recurso tierra. Este parece ser un aspecto que concita un temor espeluznante entre los terratenientes criollos. Sin embargo hay realidades que deberían ponerle los pelos de punta a los propios capitalistas. Mientras en Honduras tenemos unas 300 mil familias campesinas que no poseen tierra y que malviven de lo que producen para autoconsumo, enfrentando altos costos de los insumos que no pueden adquirir, careciendo de asistencia técnica, no son sujetos de crédito, o sea, están condenados a vivir en una calamidad permanente, de donde resulta que por todas esas carencias, ese vasto sector de la población hondureña, un poco más de tres millones, tampoco pueden participar en el intercambio mercantil al carecer de los recursos que ello requiere. Nos preguntamos, toda estrategia de desarrollo, un simple plan de gobierno o una de esas "brillantes" recetas de las agencias de desarrollo o hasta de los propios organismos multilaterales, no puede desconocer esta realidad y deberían ser los propios capitalistas y sus adláteres quienes deberían interesarse porque esta reforma se concretara; solo de esta forma se puede ampliar, organizar y cimentar el mercado nacional y ser potenciado para una inserción adecuada y con posibilidades de éxito en la economía internacional.

2. Estimular un proceso de inversión en el agro hondureño, con la finalidad de producir una diversificación productiva que genere valor agregado, empleo y nuevos recursos que sirvan para potenciar un crecimiento sostenido e incluyente. Adicionalmente, a fin de garantizar una autonomía alimentaria, el Estado no puede contemplar pasivamente la forma en que la producción del sector agroalimentario se ha reducido y profundizado con la aplicación de los programas de liberalización y apertura económica, haciendo depender la seguridad alimentaria de los hondureños de factores que están fuera del control doméstico. Por su parte, los esfuerzos y la capacidad de inversión del 
sector público se les debe complementar con una política de atracción de capital externo y nacional, que no venga a avasallar a nuestros trabajadores, que si bien es cierto se le debe garantizar la obtención de beneficios, también deberá cumplir con sus compromisos tributarios con el país y adicionalmente seguir realizando inversiones de mediano y largo plazo en el sector para apuntalar su crecimiento.

En el ámbito de la inversión pública, cobra importancia capital aquella inversión social que conlleva la creación de oportunidades en el campo, que facilite la retención de la población y el suministro de fuerza de trabajo, mediante inversiones en infraestructura, económica y social, que también desconcentre la presión demográfica sobre las grandes y ciudades intermedias.

3. En la coyuntura actual en la que se encuentra la economía hondureña la inversión es el único factor que sirve para potenciarla y propiciar el impulso motor que la empuje hacia la reactivación. Es imprescindible inducir un proceso de inversión que puede asumir varias fases: i) Proceder de inmediato a la repatriación de los capitales hondureños que están depositados en el sistema financiero y bancos extranjeros, propiciando un clima de seguridad tanto para las inversiones como para las personas; ii) adoptar medidas que induzcan una reducción del tipo de interés, a fin de descongelar y facilitar el acceso al excedente de liquidez que ha acumulado la banca nacional; iii) destinar los recursos que habían sido presupuestados para la reactivación de los sectores productivos; iv) buscar otras alternativas de financiamiento multi y bilateral en otras latitudes, ejemplo, Uniòn Europea, UNASUR, Banco del Sur, etc, buscando financiamiento concesionario para apuntalar la inversión pública; v) la reversión de la política fiscal que grava los escuálidos ingresos de la población hondureña, en momentos en que existe una contracción de la renta, 
lo que provoca peores efectos sobre el consumo; vi) reducir el encaje legal para no afectar la liquidez del sistema bancario.

4. Asumir una estrategia educativa integral que permita elevar el nivel promedio de escolaridad de los hondureños en el mediano plazo con una educación de calidad que combine la investigación, la tecnología y la innovación, que derive en un aumento importante en la productividad de la economía nacional. Un componente decisivo en esta visión es la disposición de la sociedad hondureña de realizar y destinar recursos suficientes en materia de investigación, desarrollo tecnológico e innovación, para potenciar el proceso de incremento en la productividad de los factores de la producción. Esto es una estrategia que promueva y se centre en el desarrollo de los ciudadanos hondureños.

5. Llevar a cabo una política nacional de recursos naturales y energía, en la cual el Estado, no solo sea el regulador de estos procesos, debe ser también el garante para que los servicios que se brinden, si reportan beneficios privados, que no sea en detrimento del Estado y del pueblo hondureño. Adicionalmente, se debe abogar por la conservación de las condiciones naturales que no pongan en peligro la sostenibilidad de los procesos y la reproducción de las personas. De igual forma, creo que resulta imprescindible adoptar una política en materia de combustibles que le garantice el ejercicio de su soberanía al país y que si las condiciones lo requieren, aquellos recursos que han sido enajenados por particulares y que son un factor de distorsión en el mercado, deben pasar a poder del Estado.

6. Desarrollo de macro proyectos que brinden oportunidad de nuevos empleos y que sirvan como mecanismos de vinculación e integración de regiones al proceso de desarrollo nacional. Entre esos podemos mencionar: el canal seco que conecte Puerto Cortes con la Unión, en El Salvador; mejorar el Puerto Henecàn en el Pacífico e interconectar la región noroccidental con el sector 
fronterizo trifinio que vincula a los tres países, mediante vías terrestres que vuelvan fluido el paso de personas y de bienes.

7. Propiciar una diversificación de los mercados a fin de incidir en un incremento en las exportaciones

8. El gobierno debe impulsar la repatriación de capitales nacionales que se encuentran colocados en el sistema financiero internacional, para cubrir las necesidades de recursos de inversión, la crisis fiscal en que se encuentra el país y el aislamiento externo en que lo han sumido los políticos del patio.

9. Formular un Plan Nacional de Desarrollo que nos permita rescatar la planificación, realizar una distribución adecuada de recursos en el país, promoviendo un desarrollo equilibrado e integral, que derive en la articulación del engranaje económico y en una más amplia participación e integración social.

10. Delinear una Estrategia Nacional de Empleo que no atente contra la calidad de los puestos de trabajo ni mucho menos vulnere los ingresos ni las conquistas laborales de los trabajadores.

11. Estimular una reducción en el nivel de precios, a fin de aumentar la renta disponible y mejorar la competitividad de los productos nacionales en el exterior.

12. promover una política cambiaria estable sin devaluaciones interviniendo en el mercado de divisas cuando la situación lo amerite para mantener la estabilidad cambiaria, que también tiene que ver con otros elementos o factores.

13. Liberalizar el sistema político y democratizar las formas de participación popular

14. Implementar una real estrategia anticorrupción, cimentada en la educación en el hogar, educación formal y no formal, la auditoría social, la transparencia y la rendición de cuentas en la gestión pública. 
15. La supresión de todo tipo de exoneración o exenciones fiscales, que conlleven privilegios para algunos grupos. 


\section{Bibliografía}

- José de Souza Silva: La investigación Científica y el Desarrollo de la Investigación Científica. Geopolítica del Conocimiento y los Aportes de la Ciencia a la gestión del desarrollo en América latina. Red Nuevo paradigma para la Innovación Institucional en América Latina.

- Escuela Morazanica. Programa de Desarrollo Educativo propuesto y ejecutado por el Gobierno de Carlos Roberto Reina, 1994 - 1998

- Nueva Agenda. Programa de Desarrollo Educativo propuesto y ejecutado por el Gobierno de Carlos Roberto Flores F., 1998 - 2002

- Perfil de los sistemas de salud Honduras. Monitoreo y Análisis de los Procesos de Cambio y Reforma, Febrero 2009

- Servicios y Sistemas de Salud (HSS/SP)

- Organización Panamericana de la Salud

- Organización Mundial de la salud

- Foro Nacional de Convergencia, FONAC, Estrategia de Transformación Educativa Nacional, Tegucigalpa, Honduras, 2002.

- Cuatro crisis distintas y una sola crisis verdadera y planetaria: Eric Toussaint, Dic. 2008. 